\title{
O Ensino Superior das Ciências Administrativas
}

(Traduzido, por iniciativa do Instituto Brasileiro de Ciências Administrativas, da Revista Internacional de Ciências Administrativas, vol. XXV, 1959, n. 4).

RESUMO DO EDITORIAL DA R.I.C.A.

$\mathrm{S}_{\mathrm{oB}}$ o título geral "O Ensino Superior das Ciências Administrativas", passamos a publicar alguns relatórios nacionais, apresentados ao Instituto Internacional de Ciências Administrativas, que serviram de base ao estudo feito pelo professor A. Molitor, publicado soh os auspícios da UNESCO.

Acreditamos que os trabalhos ora publicados sejam de real interêsse para todos que leram o estudo do professor Molitor e para os estudiosos em geral, porquanto incluem informaçôes pormenorizadas e mostram as tendências de cada país no setor do ensino da administração pública. Pareceu-nos, por conseguinte, que êsses trabalhos seriam excelentes documentos de consulta.

Duas foram as razões que motivaram uma seleção restrita dos vinte e sete relatórios apresentados. Em primeiro lugar, o equilibrio geográfico, a fim de que se pudesse melhor observar as diferenças e as semelhanças de conceito entre as diversas partes do mundo. E, em segundo lugar. o valor dos documentos como fonte de informações.

A principal dificuldade do professor Molitor foi unificar em uma filosofia geral um conjunto de idéias e realizações aparentemente dispares. $\mathrm{O}$ ensino da Administração Pública reflete os conceitos dominantes em cada país, e essa disparidade - que pode ocorrer também dentro de um só país decorre de diversos fatôres, entre êles a luta entre os partidários do ensino jurídico dessa matéria e os que repelem tal tendência, ou entre os que propugnam por uma educação geral e os que insistem em uma especialização.

E interessante observar as dificuldades que se originam quando se trata de definir o conteúdo da formação que devem ter os futuros funcionários do Estado. Sem nos aprofundarmos na matéria, quer-nos parecer que as opiniôes opostas resultam de uma espécie de incompreensão mútua. Em face dêsse problema, os técnicos de tôdas as partes do mundo perdem-se em considerações de semântica e de filosofia do Estado e do Direito. Entretanto, de um modo geral são as ciências administrativas consideradas um conjunto de partes de outras disciplinas. 
Consoante a forma pela qual encara o ensino da Administração Pública, cada um lhe reserva um lugar diferente no ensino superior, havendo mesmo aiguns que lhe negam o caráter de matéria de nivel universitário.

O ensino superior de ciências administrativas é um problema que se apresenta de maneira diversa em cada país, de acôrdo com as necessidades e tradições de cada um. Nos países mais antigos, cuja administração era praticada sem preparação específica, houve necessidade de se tomar conhecimento das evoluções do Estado moderno e reconheceu-se o benefício do ensino da administração. Nos países jovens impunha-se a criação de quadros habilitados a levar avante as tarefas da Administração Pública, o que tinha o risco de intensificar uma formação apressada e ineficiente. Lamenta-se apenas que não se tenham apresentado soluções verdadeiramente originais para o ensino superior dos agentes do Estado, mas, por outro lado, observa-se com satisfação que algumas experiências realizadas em outros países puderam servir de exemplo e toram, muitas vêzes, racionalmente adaptadas.

A leitura dos relatórios mostra-nos um aspecto de grande importância: apenas um país, os Estados Unidos, possui material didático completo. É, portanto, indispensável que se traduzam, se elaborem e se adaptem obras especializadas.

Concluindo, esclarecemos nossos leitores que os relatórios ora publicados constituem resposta a um questionário formulado, em 1956, pelo Instituto Internacional de Ciências Administrativas, os quais foram revisados e sua forma atual foi aprovada pelos respectivos autores.

\title{
O ENSINO DE CIENCIAS ADMINISTRATIVAS NAS ESCOLAS SUPERIORES DA UNIÃO DAS REPÚBLICAS SOCIALISTAS SOVIÉTICAS
}

\author{
(Relatório da Academia de Ciências da UI.R.S.S.) \\ I - OBSERVAÇÕES PRELIMINARES
}

O preenchimento de cargos da administração pública, na União Soviética, é feito mediante eleições (pelos deputados dos Conselhos de Trabalhadores, membros das Comissões Executivas dos conselhos locais, juizes, etc.) ou nomeação de especialistas (técnicos) no setor especifico a que se relaciona o empreendimento ou organização em pauta (e.g., engenheiros, no caso de fábricas, médicos no caso de estabelecimentos médicos, etc.). Não há, por conseguinte, disposições especiais para o treinamento de administradores profissionais, de vez que as necessárias noções básicas de ciências administrativas são ministradas, de acôrdo com cada especialidade, nos estabelecimentos gerais de ensino superior. Um ensino mais completo e especializado de ciências administrativas é, evidentemente, proporcionado nas Faculdades de Direito e de Economia, porquanto há uma procura bastante acentuada de advogados e economistas para ocuparem cargos na administração de departamentos governamentais. 


\section{II - A ORGANIZAÇÃO DO ENSINO}

Os cursos existentes têm a duração de quatro anos nos institutos de economia, de cinco nas universidades e institutos de tecnologia, agricultura e outros, de ensino superior, e de seis anos nas faculdades de medicina e outras.

As principais matérias ministradas em escolas e faculdades de direito, na preparação de estudantes para o desempenho de funções em departamentos e organizações governamentais, em Tribunais e na Procuradoria, são: teoria do Estado e do direito, história das ciências politicas, história do Estado e do direito, estatísticas sôbre litígios, princípios de contabilidade, direito constitucional, direito administrativo, finanças públicas, direito civil, direito criminal, direito de terras, processo civil, processo criminal, criminologia, direito internacional, direito de familia, lógica, latim, etc. Também são estudadas disciplinas sociais e econômicas, tais como, economia política. filosofia, etc. Os estudantes de direito devotam, ainda, parte considerável de seu tempo ao estudo de linguas estrangeiras, para que possam ler a literatura jurídica de outros paises. Os currículos das faculdades de direito prevêem também a prática de educação física e desportos.

Além das matérias obrigatórias, os curriculos incluem ainda algumas matérias facultativas, como, por exemplo, história do Estado e direito das repúblicas que compõem a União Soviética, direito civil e comercial de países estrangeiros, arbitramento e prática de arbitramento, obras públicas soviéticas, administração industrial e desenvolvimento agricola, comércio e cultura sociaista, princípios de planejamento econômico, etc. A lista de matérias facultativas é elaborada anualmente pelo corpo docente, levando-se na devida consideração os desejos dos estudantes.

O ensino nas faculdades de direito baseia-se em currículos uniformes, preparados por comissões, cujos membros são escolhidos entre professôres e catedráticos universitários de renome.

As faculdades de economia treinam os alunos para setores especializados, tais como: planejamento econômico, economia agricola, economia industrial, mão-de-obra, comércio, estatística, contabilidade, finanças e crédito, economia e organização de diferentes ramos industriais, etc. Os programas para êsses setores especializados incluem estudos sociais, econômicos e especificos destinados a prepararem os estudantes para o desempenho de funções em órgãos de planejamento de fábricas, organizações e estabelecimentos e em órgãos de administração estatal. Os estudantes de economia recebem, ademais, aulas de matemática (inclusive princípios de estatística), de tecnologia daprodução, direito civil e trabalhista, e outras matérias, o que lhes permite preencher uma grande variedade de cargos especializados.

O curso de engenharia inclui economia e organização da produção (princípios básicos de administração industrial, disciplina trabalhista, salários, seguro social, etc.). Estudam-se, também, questões relativas à organização da proteção e segurança do trabalho. Além disso ministram-se cursos especiais de ciências administrativas e economia a estudantes de agricultura, 
transporte, etc., que se preparam para preencher cargos superiores nos diversos ramos da economia nacional.

O ensino na UI.R.S.S. proporciona, além dêsses cursos de tempo integral em estabelecimentos educacionais superiores, educação superior em cursos noturnos ou por correspondência. Dos dois milhões de estudantes matriculados em estabelecimentos de ensino superior, 730.000 estão empregados. O programa de cursos noturnos ou por correspondência inclui, via de regra, as mesmas matérias, na mesma ordem e conjunto, dos programas para estudos especializados de tempo integral.

Todos os estabelecimentos de ensino superior da União Soviética são controlados pelo Estado e financiados pelo orçamento do Estado.

\section{III - CORPO DOCENTE}

Em geral, o ensino de ciências administrativas e economia é feito na U.R.S.S. por professôres altamente qualificados. Por exemplo, dos 700 professôres de disciplinas jurídicas, mais de 550 possuem graus e diplomas acadêmicos. A maioria dos professôres, antes de serem designados para cargos em estabelecimentos de ensino superior, já possuem experiência prática nos̀ setores de administração, economia ou economia planejada, em instituições estatais ou emprêsas industriais.

Os cargos de professor nos estabelecimentos superiores de ensino da União Soviética são preenchidos mediante concursos públicos, realizados cada cinco anos. O Conselho dos Estabelecimentos de Ensino Superior. após discussão pública preliminar sôbre os candidatos, faz as nomeações para os cargos, mediante escrutínio secreto.

\section{IV - ESTUDANTES}

A admissão em estabelecimentos de ensino superior na U.R.S.S. é regida por regulamentos publicados anualmente para informação do público. A fim de poderem ser admitidos, os candidatos devem possuir curso secundário. Os regulamentos não impõem requisitos de nacionalidade ou serviço militar. Para o curso normal há o limite de idade de 35 anos, ao passo que os. cursos externos estão abertos a estudantes de qualquer idade.

O acesso a estabelecimento de ensino superior é feito mediante concurso. Consoante as condições dêsse concurso, aquêles que obtêm os melhores resultados são nomeados para os primeiros lugares. Dá-se preferência a candidatos que já possuam alguma experiência prática.

A matrícula nesses estabelecimentos é gratuita. Os estudantes que cursam universidades e institutos recebem uma subvenção governamental. Há hospedarias de estudantes, instalações desportivas, clubes e outras organizações culturais pertencentes a êsses estabelecimentos. Os estudantes tomam também parte ativa na vida social e política do país. 
Todos os estabelecimentos de ensino superior possuem clubes dedicados aos diversos setores do saber. Êsses clubes unem-se para formar sociedades de estudo. A participação em tais clubes auxilia os estudantes a ampliarem seus conhecimentos e sua visão do mundo. Concedem-se prêmios aos melhores trabalhos escritos pelos membros dêsses clubes, os quais são posteriormente publicados em jornais e revistas de natureza cultural. Os estudantes externos recebem, anualmente, um mês de licença remunerada, para que possam prestar exames.

\section{$\mathrm{V}$ - EXAMES}

Os estabelecimentos de ensino superior realizam em cada ano letivo, e de acôrdo com os currículos, exames escritos para cada matéria durante todo o curso, bem como provas práticas. Êsses exames e testes são levados a cabo pelos professôres do curso. Os exames do Estado, feitos no fim do curso, são efetuados por comissões examinadoras do Estado, constituídas de professôres altamente qualificados.

\section{VI - DIPLOMAS E GRAUS}

Os estudantes que tiverem preenchido tôdas as exigências do programa, cujas teses tiverem sido aceitas e que tiverem sido aprovados nos exames do Estado, recebem um diploma certificando terem-se graduado na Universidade ou Instituto, e indicando as suas qualificações. Os estudantes que tiverem concluído cursos em departamentos externos de Universidades ou Institutos, ou em Institutos que tenham sòmente alunos externos, também recebem diploma de valor equivalente.

Ao solicitarem emprêgo para trabalho especializado os portadores de diploma de estabelecimentos de ensino superior têm preferência sôbre os candidatos que não possuirem diploma.

\section{VII - MÉTODOS DE ENSINO}

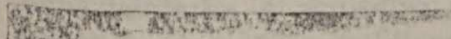

\section{1) Métodos básicos}

A instrução é proporcionada mediante aulas, conferências, seminários e trabalhos práticos. sendo que o interrelacionamento das atividades didáticas, bem como a profundidade dos cursos, embora determinados pelo programa, também estão sujeitos a modificações pelo Conselho do Instituto. O programa empresta grande ênfase à instrução prática dos estudantes, com vistas a sua atividade futura. Nas faculdades de direito, por exemplo, prevê-se que os alunos adquiram treinamento prático em departamentos governamentais, em Tribunais, na Procuradoria, etc. Os estudantes de economia adquirem prática nas seções de planejamento das emprêsas comerciais, administrações locais, etc. 
Os estabelecimentos de ensino superior da U.R.S.S. intercambiam estudantes com muitos países. Estudantes da Hungria, Polônia e Rumânia fazem cursos jurídicos na Universidade de Moscou, enquanto os estudantes de direito da União Soviética vão a outros países para fins de treinamento.

\section{Livros didáticos e material suplementar de ensino}

Fornecem-se livros didáticos e material suplementar de ensino destinados às ciências administrativas e economia para as diferentes matérias incluídas no currículo. À medida que surgirem as necessidades, os livros didáticos e o material suplementar de ensino são modificados. Está a cargo de técnicos em educação altamente qualificados bem como de associações de autores a elaboração de livros didáticos e a preparação de material suplementar de ensino. Sempre que fôr necessário concedem-se aos autores um longo periodo de licença remunerada, durante o qual possam elaborar os livros didáticos. O material suplementar de ensino inclui filmes, diagramas e equipamento visual.

\section{Organização dos assistentes do corpo docente}

Os assistentes de departamento e instituto de universidade na U.R.S.S. são nomeados após concurso público, da mesma forma que os professôres. Os assistentes de laboratório são selecionados na faculdade respectiva entre candidatos possuidores de habilitações especiais. Os monitores dos diversos cursos e grupos são designados pelos diretores das faculdades, escolhidos entre os alunos, de acôrdo com as organizações estudantis.

\section{VIII - TRABALHOS DE PESQUISA}

Em tôdas as faculdades das Universidades do Estado, nos Institutos de economia e nos departamentos de técnica superior e institutos agrícolas para economia e organização da produção, o ensino está ìntimamente ligado a trabalhos de pesquisa em larga escala conduzidos de acôrdo com planos elaborados pelos próprios institutos. Os trabalhos de pesquisa levados a cabo em estabelecimentos de ensino superior auxiliam a evolução dos estudos e a elevação do padrão de ensino das disciplinas relativas à administração. Os trabalhos escritos por professôres e outros especialistas são grandemente difundidos através de relatórios e compilações publicados pelo estabelecimento e também por jornais especializados tais como "A Lei e o Estado Soviético", "Princípios Legais Socialistas", etc. Há uma editôra estatal para literatura juridica que publica uma grande quantidade de livros didáticos, material suplementar de ensino, monografias, folhetos e outros materiais para o estudo do direito. As diversas editôras técnicas publicam também monografias e compilações relativas a vários aspectos da organização e administração industrial. Tudo isso permite uma ampla divulgação dos problemas científicos de administração, dando margem, assim, a uma discussão construtiva dêsses problemas. 


\title{
O ENSINO UNIVERSITÁRIO DE ADMINISTRAÇÃO PÜBLICA NOS ESTADOS UINIDOS
}

\author{
Frank B. Cliffe JR. \\ Professor Assistente da Universidade Estadual \\ de Michigan
}

\section{INTRODUÇÃO}

No presente relatório, alguns pontos do questionário elaborado pelo IICA são atendidos resumidamente e outros são omitidos; de uma maneira geral, procurou-se mostrar alguns aspectos da matéria em que a experiência dos E.U.A. possa ser de maior interêsse para um público internacional. Uma resposta completa ao questionário seria, no que se refere aos Estados Unidos, impossivel sem muita pesquisa e viagem. O que se segue não é, por conseguinte, o resultado de um trabalho tão amplo, mas constitui apenas a opinião de um indivíduo, auxiliado por sugestões (nem sempre aceitas) de algumas pessoas que tiveram a bondade de ler nosso trabalho.

Uma excelente descrição do treinamento para administração pública, nos Estados Unidos, pode ser encontrada no livro de George A. Graham, Education for Public Administration (Chicago, Public Administration Service, 194i, 366 páginas). Essa importante obra foi escrita após ter o autor passado um ano, sob os auspícios da Comissão de Administração Pública do Conselho de Pesquisas de Ciências Sociais, fazendo um levantamento dos programas em vigor nos E.U.A. e visando vinte universidades. Embora já se tenha obtido considerável progresso durante os quinze anos que se passaram desde a publicação do livro, o material analítico, descritivo e comparativo que encerra é ainda de real valor.

\section{UNIVERSIDADES}

O ensino das ciências administrativas, nas universidades, é geralmente ministrado através do departamento de ciência politica. O estudo elaborado pela Public Administration Clearing House, sôbre o treinamento de extensão universitária em administração pública, revelou que quase dois terços das instituições incluídas nesse estudo ensinam administração pública num departamento de ciência politica ou de estudos governamentais. Quase um têrço das outras universidades possui escola separada de administração pública. As poucas instituições restantes ministram aulas de administração pública em escolas de ciência política e social, ou de ciência politica e história, etc.

Os cursos são programados de maneira a que tanto estudantes universitários como funcionários públicos os possam freqüentar. Na maioria das cidades em que há um grande número de funcionários públicos, as universidades dão considerável importância ao treinamento em serviço, freqüentemente proporcionando aulas noturnas ou no final da tarde, destinadas principalmente a funcionários públicos; todavia, não raro podem essas aulas ser assistidas também por estudantes cursando a universidade. 


\section{CURRÍCULOS}

É extremamente heterogêneo o ensino de administração nos Estados Unidos, e é provável que o país tenha lucrado muito por ter podido contar com uma grande variedade de métodos para o estudo da administração. As cidades, os estados e a nação têm incumbido seus administradores de tarefas acentuadamente dispares, que requerem tipos diversos de treinamento acadêmico. Pode-se dizer, de maneira geral, que os Estados Unidos não são apenas grandes em superfície, mas possuem uma composição múltipla, devendo-se, pois esperar diversidade quanto aos currículos. É difícil determinar uma linha divisória precisa entre "ensinamentos de cultura geral" e "treinamento especializado". Muito poucas universidades americanas, se as pudermos encontrar, ministram ensino correspondente a uma educação geral como o faz, e. g., a Universidade de Oxford. Entretanto, pràticamente tôdas as universidades americanas exigem um "curso geral de lingua inglêsa" e, salvo poucas exceções, os estudantes recebem alguns ensinamentos de humanidades e de ciências físicas. Talvez seja certo dizer-se que um estudante universitário típico recebe mais "treinamento especializado" do que seu colega inglês ou da Europa Continental. Esse estudo especializado abrange, porém, muitas disciplinas acadêmicas, sobretudo, para o estudante de administração, as várias ciências sociais.

Talvez seja êste o momento adequado para se indicar um importante aspecto da administração tal como é praticada nos Estados Unidos. A maioria dos administradores tem sido recrutada entre grupos profissionais liberais, homens que até então tinham passado a maior parte de suas carreiras no govêrno na qualidade de médicos, advogados, cientistas, cada qual com o respectivo curso acadêmico. O tempo dedicado ao estudo de administração nas demais escolas profissionais, que não as de administração, varia, mas é raro dar se muita atenção a essa matéria. (Por outro lado, em certo número de escolas profissionais, o ensino de administração tem tido uma importância crescente, o que, de maneira geral, deverá beneficiar o conhecimento administrativo).

A maioria dos estudantes de administração pública, antes da segunda guerra mundial, ao sair da Universidade, ia trabalhar num grupo de pesquisas ou num órgão de assessoramento junto ao govêrno; as funções de linha ficavam geralmente reservadas aos especialistas técnicos, em lugar de serem entregues àqueles que tinham estudado administração. Hoje em dia essa situação está bem modificada, havendo um maior número de estudantes de administração ocupando cargos de linha.

$U_{m}$ dos maiores grupos profissionais do serviço público dos Estados Unidos é o dos advogados (embora muitos funcionários públicos que possuam diploma de bacharel em direito não ocupem cargos que possam ser classificados como "jurídicos"). Nem todo o ensino de direito administrativo é proporcionado em escolas de direito, mas o é em sua maior parte. São os advogados e os professôres de direito os principais defensores da tese de que o direito constitui elemento fundamental do processo administrativo.

Administração comparada é um campo de estudos surgido recentemente nos Estados Unidos. Muitas Universidades vêm ministrando já há alguns 
anos aulas de "govêrno comparado", estudos êsses que geralmente tratam do exame de diversos tipos de estruturas de govêrno da Europa, mas nos quais a comparação sistemática desempenha papel decididamente pouco importante. Durante os últimos 5 ou 10 anos, entretanto, um número crescente de universidades tem iniciado programas sistemáticos de administração comparada, estudando inclusive paises não ocidentais.

Há uma considerável interpenetração entre o currículo de administração e o das outras matérias. Estudantes de administração e de direito raras vêzes freqüentam os mesmos cursos (exceto na medida em que sejam obrigatórios para todos os estudantes da Universidade), mas aos estudantes de ciências sociais é comum ser permitido e até exigido fazer cursos de outras especialidades.

Relações entre administração pública e de emprêsas. - Nos E.U.A. muitas pessoas passam da administração pública para a administração privada e vice-versa. Essa mobilidade pràticamente não tem qualquer efeito na estrutura das Universidades, porquanto há muito pouco contato entre os estudantes ou professôres, nos dois setores. Da mesma forma, as associações profissionais preocupam-se em geral exclusivamente com administração pública ou de emprêsas, conforme o caso, raramente aventurando-se além de seus respectivos dominios.

Fizeram-se várias análises das diferenças entre os dois setores. $\mathrm{O}$ Sr. Herbert Emmerich lembrou uma diferença muito importante. No mundo de negócios, a responsabilidade do administrador é usualmente pelo resultado final, o lucro liquido, por exemplo, ao passo que o administrador público, nos Estados Unidos, poderá ser chamado a prestar contas, pelo Congresso ou pelo público, de pormenores insignificantes. É o caso concreto, e não o programa geral, que costuma gerar sérias controvérsias. As razões dessa diferença são complexas, e se considerarmos a ideologia democrática os resultados são em muitos casos benéficos. Com isto, porém, torna-se necessário que a organização $e$ as práticas sejam diferentes na administração pública e na de emprêsas, o que constitui um dos fatôres de desestimulo ao conjunto de administração pública e de emprêsas.

A cooperação internacional na administração tem sido, nos Estados Unidos, grandemente apoiada por organizações oficiais e extra-oficiais. Ésse apoio tem diversas causas, entre as quais a idéia de que uma administração eficaz é essencial para que haja uma cooperação técnica em geral; outra razão, não menos importante, é o reconhecimento de que há liçôes a serem aprendidas da experiência e do conhecimento administrativo de ultramar.

Estabelecimentos de treinamento após nomeação. - Não possuem os Estados Unidos escola geral para treinamento de funcionários públicos fora das universidades. De tempos a tempos tem-se considerado sèriamente a criação de uma escola dessa natureza, tendo sido dados alguns passos hesitantes para a concretização dêsse objetivo. Apenas alguns dos serviços governamentais possuem escolas de pessoal. Entre essas, as que mais se sobressaem são as das Fôrças Armadas (Colégio Nacional de Guerra, Colégio Industrial das Fôrças Armadas, Escola de Estado Maior das Fôrças 
Armadas). O Instituto de Relações Exteriores do Departamento de Estado inaugurou recentemente um programa de treinamento bastante ambicioso para funcionários do corpo diplomático e para os funcionários da Secretaria de Estado, em Washington. O Instituto foi ampliado e tornou a diminuir por diversas vêzes, nas duas últimas décadas, e essa espécie de treinamento ainda terá que se desenvolver mais para que possa atingir uma base realmente estável. A "Graduate School" do Departamento de Agricultura dos Estados Unidos tem uma longa experiência na qualidade de organização semi-oficial, oferecendo cursos aos funcionários do Ministério.

Esses estabelecimentos governamentais são financiados mediante dotações legislativas através da iniciativa dos respectivos ministérios em geral como resultado das recomendações de uma comissão consultiva independente. São êles organizados pelos Ministérios, principalmente para os seus próprios funcionários, embora freqüentemente seja permitido a alguns funcionários de outros ministérios e mesmo de entidades privadas participarem de alguns dos trabalhos.

Corpo docente. - A maior parte do ensino de administração pública é ministrada por pessoal de tempo integral. O corpo docente é, não raro. suplementado por elementos com experiência prática na disciplina, recrutados para fazerem conferências isoladas ou conduzirem seminários. Êsses elementos podem ou não ser pagos pelos seus serviços e se o forem é geralmente em base nominal. Quanto ao corpo docente de tempo integral aconselha-se que o mesmo tenha alguma experiência com o govêrno. Há uma mobilidade bastante acentuada entre os diversos tipos de trabalhos nos Estados Unidos e é comum encontrar-se uma "carreira" em que se deu o exercício de um cargo num e noutro govêrno, em uma universidade ou em emprêsa privada e, ainda, em organizações de fins lucrativos. Muitos professôres de tempo integral iniciam o seu trabalho de ensino antes de terem adquirido o grau de Ph. D., ("Philosophy Doctor"), mas o doutorado constitui um requisito para que se possa conseguir algum progresso na carreira, sobretudo nas grandes universidades.

Estudantes. - Os estudantes de ciências administrativas, antes de serem nomeados para qualquer emprêgo governamental, não são considerados membros do funcionalismo público e não possuem qualquer direito a que o govêrno lhes dê emprêgo após a conclusão de seus estudos. Por outro lado. há uma crescente oportunidade (ainda não totalmente difundida) para funcionários públicos tirarem licenças, remuneradas ou não, a fim de continuarem os seus estudos em uma universidade, e êsses estudantes têm geralmente um cargo a sua espera após a conclusão de seus estudos.

Exames. - Na maioria das universidades os estudantes prestam exames após conclusão dos cursos individuais e freqüentemente são-lhes dados vários testes no decorrer do curso. No nivel de pós-graduação, há geralmente exames escritos ou orais após a conclusão dos cursos para obtenção dos graus de "Master" e "Doctor" (Ph. D.) e após ter sido aceita a tese ou dissertação.

Para os estudantes universitários há uma grande variedade de técnicas de exame que está sendo empregada cada vez mais nos últimos anos, sobre- 
tudo exames "objetivos" que podem ser corrigidos fàcilmente e mesmo, muitas vêzes, com o auxílio de máquinas. Os exames "subjetivos", isto é, ensaios, talvez infelizmente, são usados cada vez em menor escala, embora continuem a ser a forma típica de exame no nivel de estudantes possuidores de diploma (pós-graduação), onde há sempre um número pequeno, o que permite a utilização dêsse tipo de prova. As juntas examinadoras são constituídas por membros do corpo docente.

Diplomas - Concedem-se vários tipos de diploma após conclusão dos programas de estudo... Master of arts, master of sciences, doutor em filosofia e doutor em administração pública constituem diplomas típicos concedidos pela universidade. Muitos programas de treinamento em serviço concedem prêmios, diplomas ou certificados. Qualquer que seja porém o tipo de diploma, raras vêzes dá êle ao possuidor qualquer direito legal ou moral a um cargo governamental. Em muitos casos, entretanto, constitui requisito formal ou implícito - e nem sempre bastante - para obtenção de emprêgo.

Métodos de ensino - O curso típico de pós-graduação nas universidades americanas é conduzido por um professor de tempo integral, e consiste de uma combinação de conferências e seminários nos quais os estudantes desempenham importante papel sob a orientação do professor. Tornam-se cada vez mais populares os estudos feitos sôbre casos concretos que. se usados de maneira adequada, trazem sem dúvida alguma grandes benefícios para os estudantes. Os estudos levados a efeito em locais de trabalho, assim como viagens e visitas a estabelecimentos governamentais, são muito comuns. Exige-se geralmente dos estudantes a elaboração de teses e trabalhos escritos, que não são freqüentemente discutidos por tôda a classe em conjunto. Algumas escolas, especialmente as que se dedicam primacialmente ao treinamento de funcionários públicos, concedem bôlsas para estagiários. São bastante comuns encontros para debates entre os estudantes e elementos que possuem experiência prática da matéria.

Uma das poucas generalizações que se podem fazer sôbre métodos de ensino é a aceitação difundida (mas não universalmente) da necessidade de participação do estudante no processo de ensino. A participação é considerada como uma técnica capaz de desenvolver o interêsse e a motivação do estudante. $\mathrm{O}$ argumento é que, por meio de seminários, debates e outras formas de participação do estudante, em vez de simplesmente pelo método direto de preleções, um maior número de conceitos e idéias, assim como um conhecimento mais amplo, podem ser proporcionados.

Livros didáticos - Não há pràticamente limite quanto ao número de livros didáticos disponível sôbre administração pública. Alguns tratam da matéria de forma genérica, outros encaram aspectos especializados da mesma. A maioria das grandes companhias editôras de livros didáticos do país possui um grande número de livros sôbre administração que podem ser fàcilmente obtidos para trabalhos universitários.

Além disso, muitos outros tipos de publicações são usados nas diversas universidades, tais como documentos governamentais, publicações periódicas e mesmo romances de ficção. Há disponível uma série de livros de trechos selecionados. 
Universidade - contatos oficiais - Varia grandemente a intimidade nas relações entre as universidades e o "futuro ambiente de trabalho" dos estudantes. A maioria dos contatos são de natureza informal, na maior parte das vêzes ocasionada por transferência do funcionário, do govêrno para a universidade, e de volta ao trabalho governamental. Uma variação dêsse quadro é o número crescente de contratos que o govêrno faz com as universidades, para a prestação de vários tipos de serviço. Um exemplo conhecido é a cooperação técnica entre os Estados Unidos e universidades estrangeiras, financiadas pela Administração de Cooperação Internacional e seus predecessores.

A Sociedade Americana de Administração Pública, juntamente com a Sociedade Americana de Ciências Politicas, representam importantes pontos de reunião comum para estudantes, professôres e técnicos de administração.

Pesquisas - O fato de que as ciências administrativas são ensinadas de maneira extensa nos Estados Unidos sem dúvida contribuiu muito para o desenvolvimento de pesquisas científicas (1) neste setor. É responsabilidade dos professôres norte-americanos, assim como em qualquer parte, levar a efeito pesquisas e publicar os resultados de seus trabalhos. Não há dúvida de que se tem produzido bastante trabalho de pesquisa no setor da administração. Essa pesquisa científica tem sido conduzida durante anos e ao que parece existe hoje um interêsse cada vez maior pela pesquisa.

Talvez o maior centro institucional para pesquisas em administração pública nos Estados Unidos esteja localizado no número 1.313 do Leste da Rua 60, Chicago, Illinois, onde quatorze organizações autônomas mantêm seus escritórios centrais. A maioria dessas organizações possui entre seus sốcios vários tipos de funcionários públicos, municipais, estaduais e alguns federais. Sua principal função é a de prestar serviços a seus sócios, não tendo como objetivo básico trabalhos de pesquisas. Não obstante, ao levar a cabo suas várias funções (conferências anuais e pequenas reuniões, publicações em jornais, serviços de inquérito, etc.) executam considerável trabalho de pesquisa, cujos resultados são amplamente divulgados, não apenas entre os seus próprios associados mas também entre as organizações co-irmãs, chegando, por conseguinte, ao conhecimento de milhares de funcionários públicos e professôres de administração, em todo o território dos Estados e do exterior.

A maioria das universidades estatais mantém escritórios de administração pública nos quais a mais importante atividade é a pesquisa prática, realizada em repartições estaduais e municipais. Muitos estudantes universitários entram para o campo da administração através de estudos nesses escritórios ou trabalhando nos levantamentos que os mesmos efetuam.

(1) O têrmo "ciência" é utilizado de maneira mais cautelosa nos Estados Unidos hoje em dia do que no passado. A aceitação geral de uma definição mais critica e e mais elaborada do que constitui uma ciência torna claro que muito do que se tem, escrito e pensado sôbre administração, năo obstante a utilidade que tiver, dificilmente pode ser considerado como ciência. Os positivistas lógicos e os administradores tradicionais podem chegar a um acôrdo quanto a êsse aspecto mediante simplesmente o uso da expressão "ciência e arte" da administração. 
O grosso da pesquisa teórica ou básica em administração pública é feito pelos professôres universitários, quer individualmente quer na qualidade de membros de grupos de pesquisa. Além disso, os funcionários públicos freqüentemente devotam grande parte de seu tempo a trabalhos de pesquisa. Os resultados dêsses trabalhos têm muitas vêzes aplicações imediatas e óbvias. Em alguns casos, sobretudo no Departamento da Defesa, são levados a efeito, com regularidade, estudos de natureza altamente teórica.

Os resultados das pesquisas são publicados em uma grande variedade de jornais e revistas, desde os mais empiricos e especializados até os altamente teóricos. Como exemplo citamos: "Public Administration Review", - "American Political Science Review", "Management Science", "Administrative Science", "Journal of the Operations Research Society of America", "Advanced Management" e, secundàriamente, a maioria das publicações de diversas sociedades de ciências sociais e de natureza interdisciplinar, tais como "Behavioral Sciences", "Human Organization" e "Human Relations". Além dessas publicações, há monografias e livros em profusão. 